en diversos sustratos a temperatura ambiente en condiciones de invernadero. Se evaluó la respuesta del enraizamiento al ácido Indol-butírico (IBA) a los 30, 60, 90 y 120 días.

\section{RESULTADOS Y CONCLUSIÓN}

Los resultados muestran que la mejor época para la colecta de $B$. magellanica es el periodo invernal. El porcentaje de sobrevivencia de los esquejes es superior al $90 \%$ sin aplicación de hormonas. El enraizamiento de los esquejes ya era detectable a los 30 días de tratamiento y alcanzó el $90 \%$ a los 90 días de tratamiento con IBA.

Las plantas obtenidas por esquejes colectados en junio del 2004 han sido exitosamente trasplantadas al exterior donde se han aclimatado favorablemente. En este momento se ha dado inicio a la fase de domesticación a través de podas de establecimiento y técnicas de manejo cultural. Se concluye que el romerillo enano es una especie nativa chilena muy promisoria para la floricultura ornamental. *

* Trabajo financiado por el Proyecto FIA-PI-C-2002-1-A-070/Universidad de Magallanes

Agro Sur 34 (1-2): 20-21 2006

\title{
PROPAGACIÓN DE Pteris chilensis Desv. CON FINES ORNAMENTALES
}

\section{PROPAGATION OF Pteris chilensis Desv. WITH ORNAMENTAL PURPOSE}

\author{
Letelier, L. y Peñailillo, P. \\ Instituto de Biología Vegetal y Biotecnología. Universidad de Talca. Casilla 747 - Talca. \\ E-mail: lealg79@alumnos.utalca.cl
}

\section{INTRODUCCIÓN}

La importancia agronómica del cultivo de helechos radica, principalmente, en el uso ornamental que se les da. De ello surge la necesidad de domesticar nuevas especies, desarrollar nuevos cultivares y mejorar las técnicas de cultivo ya existentes. Aunque, los Pteridófitos chilenos representan solo un $1,5 \%$ de la flora mundial de este taxón, con 125 especies y 41 taxa infraespecíficos (Rodríguez, 1995), su endemismo es de los más altos dentro del cono sur, con un $15 \%$ en Chile Continental y un $18 \%$ en el Archipiélago de Juan Fernández (Ponce et al., 2002). Todos susceptibles de ser domesticado para fines ornamentales. En la VII Región crecen 37 taxones, muchos de los cuales habitan áreas restringidas y bajo bosques fragmentarios, como aquel de hualo (Nothofagus glauca) y ruil (N. alessandrii). En esta situación se encuentra Pteris chilensis (Peñailillo, 1989), lo cual nos llevó a seleccionarlo como material de estudio para desarrollar una metodología de cultivo a través de esporas, contribuyendo tanto al conocimiento de propagación de helechos nativos, sus requerimientos culturales, como a mejorar su estado de conservación "ex situ".

\section{MATERIAL Y MÉTODO}

Se recolectaron esporas de individuos de Pteris chilensis de una población ubicada en la Provincia de Cauquenes, Séptima Región, Carretera Cauquenes - Pelluhue, sector "El Corte" ( $35^{\circ} 49^{\prime}$ Lat. S $72^{\circ} 32^{\prime}$ Long. W, y a $90 \mathrm{~m} \mathrm{snm}$ ). Las esporas fueron recolectadas de individuos adultos y con esporangios maduros y cerrados. Las frondas completas fueron trozadas y guardadas dentro de sobres de papel debidamente rotulados y puestas a secar a temperatura ambiente. Al cabo de tres semanas, las esporas ya liberadas de los esporangios fueron limpiadas con un juego de tamices de $200-125-85 \mu \mathrm{m}$. Una vez limpias, las esporas, fueron conserva- 
das en frascos plásticos esterilizados previamente con luz UV y dejadas a $5^{\circ} \mathrm{C}$.

1.- Cultivo in vitro de esporas. Con el objeto de registrar los estadios y el tiempo de duración de los mismos desde la germinación hasta la formación de la primera fronda se montaron seis placas Petri con medio nutritivo de Thompson, las cuales se colocaron en una cámara de cultivo Biotronette Mark III, con un fotoperíodo de 12 horas de luz y una temperatura promedio de $25^{\circ} \mathrm{C}$. Se realizaron observaciones microscópicas periódicas y se registraron mediante fotomicrografías los diferentes estados de desarrollo.

2.- Ensayo de densidad de siembra. Se sembraron esporas a dosis de siembra de 5,10 y $15 \mathrm{mg}$ en potes plásticos $(12,5 \times 18,5 \times 7 \mathrm{~cm})$, sobre sustrato de turba y arena (1:1), los cuales se colocaron en las mismas condiciones ambientales del ensayo anterior. porcentaje de gametófitos sexuales el cual oscila en un $30 \%$. Donde sí se aprecian diferencias es en el número de esporófitos, se evidencia que a mayor dosis, se adelanta la aparición de espo-

\section{CONCLUSIONES}

El cultivo de esporas en sustrato de arena y turba se valida como técnica para cultivar gametófitos de Pteris chilensis siendo este método efectivo para obtener esporófitos jóvenes con tres hojas en promedio al cabo de 250 días.

El efecto de la densidad de siembra es selectivo, afectando morfológicamente al gametófito al disminuir su tamaño pero no así la forma cordiforme que ellos presentaban. La dosis de siembra más alta afectó significativamente el desarrollo de esporófitos al acortar el periodo vegetativo y aumentar las probabilidades de en-

Cuadro 1. Efecto de la dosis de siembra sobre la forma y tamaño de los gametófitos.

Table 1. Effect of sowing rate on the shape and size of the gametophytes.

\begin{tabular}{cccccccc}
\hline TRAT. & $\begin{array}{c}\text { Densidad } \\
\text { de siembra } \\
(\mathbf{m g})\end{array}$ & $\begin{array}{c}\text { Forma } \\
\text { gametófito }\end{array}$ & $\begin{array}{c}\text { Gametófito } \\
\text { sexuales } \\
\%\end{array}$ & $\begin{array}{c}\text { Largo } \\
\text { gametofito } \\
\text { sexual } \\
(\mathbf{m m})\end{array}$ & $\begin{array}{c}\text { Ancho } \\
\text { gametófito } \\
\text { sexual } \\
(\mathbf{m m})\end{array}$ & $\begin{array}{c}\text { Relación LiA } \\
\text { Gametófito } \\
\text { Sexual }\end{array}$ & $\begin{array}{c}\text { Número* } \\
\text { esporófitos }\end{array}$ \\
\hline $\mathrm{T} 1$ & 5 & $\begin{array}{c}\text { Cordiforme } \\
\text { Alas simetricas }\end{array}$ & 31,7 & $3.8 \mathrm{a}$ & $2.3 \mathrm{a}$ & $1.7 \mathrm{a}$ & $1 \mathrm{a}$ \\
$\mathrm{T} 2$ & 10 & $\begin{array}{c}\text { Cordiforme } \\
\text { Alas simétricas }\end{array}$ & 31,8 & $2,6 \mathrm{~b}$ & $1,3 \mathrm{~b}$ & $1,4 \mathrm{ab}$ & $2 \mathrm{ab}$ \\
& 15 & $\begin{array}{c}\text { Cordiforme } \\
\text { Alas simétricas }\end{array}$ & 28.3 & $2,0 \mathrm{~b}$ & $1,6 \mathrm{c}$ & $1,3 \mathrm{~b}$ & $5 \mathrm{~b}$ \\
\hline
\end{tabular}

* número de cuadrantes $(\mathrm{n}=65)$ que presentan esporófito al cabo de 200 días de sembrados.

Los valores de cada columna con distinta letra son significativos $\mathrm{P}<0.05$

\section{RESULTADOS}

La germinación de las esporas ocurrió entre los 10 y 12 días, siendo del tipo Vinaria. La fase filamentosa de 4-5 células se produjo entre los 23-24 días. A los 60 a 90 días se obtuvo un gametófito cordiforme de alas simétricas. La aparición de órganos sexuales fue entre los 60 a 95 días, apareciendo primero los arquegonios y luego los anteridios. Finalmente, la primera fronda se observó a los 115 días, lográndose un esporófito con 3 a 4 frondas al cabo de 250 días. La densidad (Cuadro 1), afecta el tamaño de los esporófitos pero no su forma. Los porcentajes de germinación no se ven afectados por el aumento en la dosis de siembra, tampoco el cuentro de los gametos. De esta manera el protocolo ejecutado es susceptible de usarse como método de propagación de Pteris chilensis.

\section{BIBLIOGRAFÍA}

PEÑAILILLO, P. 1989. Los Pteridófitos de la Región del Maule. Trabajo inédito. Investigación para curso de Pteridófitos. Universidad de Concepción.

PONCE, M.; MEHLTRETER, K.; DE LA SOTA, E. 2002. Análisis biogeográfico de la diversidad Pteridofítica en Argentina y Chile Continental. Revista Chilena de Historia Natural 75: 703-717.

RODRÍGUEZ, R. 1995. Parte Descriptiva: Pteridophyta. In: Marticorena, C; Rodríguez, R. (eds.). Flora de Chile. Vol. I Pteridophyta - Gymnospermae. Concepción, Universidad de Concepción, pp. 119-309. 